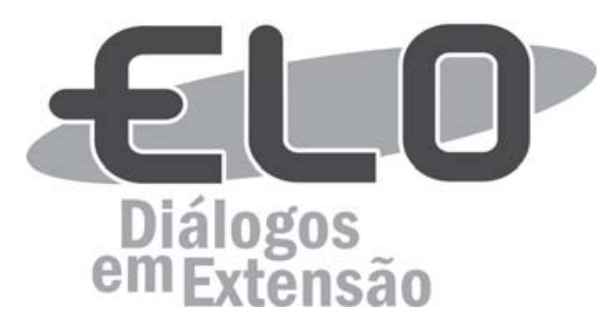

\title{
Projeto Sabão Ecológico: uma estratégia educacional para a reciclagem do óleo de cozinha no municipio de Viçosa
}

\author{
Yaankha Bharbara Allecxandria Bernardo da Silva Barbosa \\ Cardoso $^{1}$, Sabrina Marcelino Amoglia ${ }^{2}$, Julie Louise McClelland ${ }^{3}$, \\ Amanda Ferreira Teixeira ${ }^{4}$ Laura Fernandes Melo ${ }^{5}$
}

Resumo: O descarte inadequado de resíduos de óleo de cozinha usado pode causar danos ambientais no local onde é depositado, bem como no entorno, fato que desrespeita um dos direitos do ser humano: o acesso a um ambiente ecologicamente equilibrado. Nesse contexto, o Projeto Sabão Ecológico foi criado pela ONG Engenheiros Sem Fronteiras - Núcleo Viçosa, em função da necessidade de sensibilizar a população sobre os danos inerentes ao descarte incorreto desse óleo. Por meio de oficinas teórico-práticas, que ensinam a produção de sabão artesanal a partir do óleo usado, o projeto apresenta um destino sustentável para este, gerando um produto capaz de auxiliar no orçamento doméstico ou mesmo gerar renda para a comunidade, já tendo alcançado avaliação positiva pelos participantes. Dessa forma, o projeto tem impactado diversas esferas, pois promove benefícios ambientais, sociais e financeiros aos envolvidos por meio da educação ambiental, utilizada como ferramenta de transformação da sociedade.

Palavras-chave: Sabão ecológico. Educação ambiental. Sustentabilidade.

Área Temática: Educação, Meio Ambiente.

\section{Ecological Soap Project: an educational strategy for the recycling of cooking oil in the municipality of Viçosa}

Abstract: Improper disposal of waste cooking oil can cause environmental damage to the place where it is disposed of, as well as the environment, a fact that disrespects one of the rights of the human being: access to the ecologically balanced environment. In this context, the Ecological Soap Project was created by the NGO Engineers Without Borders- Core Viçosa, due to the need to educate the population about the damages inherent in the incorrect disposal of this oil. Through theoretical-practical workshops that teach the production of handmade soap from the oil used, the project presents a sustainable destination for the same, generating a product capable of assisting in the domestic budget or even generate income for the community, having already positive evaluation by the participants. In this way, the project has impacted several spheres, promoting environmental, social and financial benefits to those involved, through environmental education, used as a tool for transforming society.

Keywords: Ecological soap. Environmental education. Sustainability.

\footnotetext{
${ }^{1}$ Universidade Federal de Viçosa. Estudante de Graduação em Bioquímica. (yaankha@gmail.com).

${ }^{2}$ Universidade Federal de Viçosa. Estudante de graduação em Engenharia de Alimentos.

${ }^{3}$ Universidade Federal de Viçosa. Estudante de Graduação em Bioquímica.

${ }^{4}$ Univiçosa. Estudante de Graduação em Engenharia Química.

${ }^{5}$ Universidade Federal de Viçosa. Professora do Departamento de Engenharia de Alimentos.
} 


\section{Proyecto Jabón Ecológico: una estrategia educativa para la reciclaje del aceite de cocina en el municipio de Viçosa}

Resumen: El descarte inadecuado de residuos de aceite de cocina usado puede causar daños ambientales en el lugar donde es descartado, así como en el entorno, hecho que no respeta uno de los derechos del ser humano: el acceso a un ambiente ecológicamente equilibrado. En ese contexto, el Proyecto Jabón Ecológico fue creado por la ONG Ingenieros sin Fronteras - Núcleo Viçosa, debido a la necesidad de concientizar a la población sobre los daños inherentes al descarte incorrecto de ese aceite. Por medio de talleres teóricoprácticos que enseñan la producción de jabón artesanal a partir del aceite usado, el proyecto presenta un destino sostenible para el mismo, generando un producto capaz de auxiliar en el presupuesto doméstico o incluso generar ingresos para la comunidad, ya teniendo alcanzando una evaluación positiva por parte de los participantes. De esa forma, el proyecto ha impactado diversas esferas, pues promueve beneficios ambientales, sociales y financieros a los involucrados a través de la educación ambiental, utilizada como herramienta de transformación de la sociedad.

Palabras clave: Jabón ecológico. Educación ambiental. Sostenibilidad.

\section{Introdução}

Segundo o Artigo 225 do Capítulo VI da Constituição Brasileira de 1988, todos os brasileiros têm direito ao meio ambiente ecologicamente equilibrado, sendo responsabilidade tanto do Poder Público quanto da coletividade defendê-lo e preservá-lo para as presentes e futuras gerações (BRASIL, 1988). No parágrafo $1^{\circ}$ deste mesmo artigo, é mencionado que uma das formas de se assegurar a efetividade desse direito inalienável de qualquer cidadão é o Poder Público promover a educação ambiental, em todos os níveis de ensino, e a conscientização pública para a preservação do meio ambiente (BRASIL, 1988). De acordo com a Política Nacional de Resíduos Sólidos, instituída pela lei $n^{\circ} 12.305$, de 2 de agosto de 2010, é de responsabilidade do poder público, de iniciativas privadas e da coletividade a efetivação das ações asseguradas por este mesmo documento, que incluem, o estímulo à adoção de práticas sustentáveis, incentivo à indústria de reciclagem, redução do volume de resíduos gerados e capacitação contínua sobre os resíduos sólidos (BRASIL, 2012).

Segundo Nelson Mandela, a educação é o instrumento com maior potencial transformador da sociedade (Gomes, 2017), consistindo, portanto, de uma ferramenta capaz de garantir a segurança ambiental para as futuras gerações, catalisando a mudança comportamental dos indivíduos e, por conseguinte, modificando a maneira como o ser humano se relaciona com o meio ambiente. Assim, a educação ambiental pode ser vista como um meio seguro de se implantar o ideal transformador nos indivíduos e, por conseguinte, promover a conscientização necessária para garantir esse direito assegurado pela própria Constituição do Brasil.

De acordo com a Política Nacional de Educação Ambiental - Lei nº 9795/1999, Artigo 1:

Entendem-se por educação ambiental os processos por meio dos quais o indivíduo e a coletividade constroem valores sociais, conhecimentos, habilidades, atitudes e competências voltadas para a conservação do meio ambiente, bem de uso comum do povo, essencial à sadia qualidade de vida e sua sustentabilidade. (Brasil, 1999).

Já as Diretrizes Curriculares Nacionais para a Educação Ambiental indicam uma definição um pouco distinta da anterior, permitindo uma visão um pouco mais ampla e complementar à oferecida pela Política Nacional de Educação Ambiental:

\footnotetext{
A Educação Ambiental é uma dimensão da educação, é atividade intencional da prática social, que deve imprimir ao desenvolvimento individual um caráter social em sua relação com a natureza e com os outros seres humanos, visando potencializar essa atividade humana com a finalidade de torná-la plena de prática social e de ética ambiental. (Brasil, 2012).
}

Em razão disso e com a ideologia de que não cabe somente ao Poder Público e às empresas privadas trabalhar pela preservação do meio ambiente, sendo incumbência de todos trabalharem em 
prol do ambiente em que vivemos, a ONG Engenheiros Sem Fronteiras - Núcleo Viçosa, desenvolveu o Projeto Sabão Ecológico por meio de práticas sociais que prezem pela sustentabilidade. Esse projeto foi idealizado para propiciar um descarte correto para o óleo de cozinha usado, no município de Viçosa, Minas Gerais. Para isso, foram realizadas oficinas que ensinaram aos participantes a produção do sabão ecológico e informaram a eles os danos ao meio ambiente causados pelo descarte inadequado desse resíduo que também afeta a saúde humana.

A prática de fritura, comumente utilizada no preparo de alguns alimentos, é realizada diariamente em diversos lares brasileiros (Esen, 2009), gerando, anualmente, cerca de 9,0 bilhões de litros de óleo de cozinha, sendo que destes estima-se que apenas 2,5\% são reciclados (Santos, 2009), havendo a possibilidade de o restante ser descartado, de maneira inadequada, no meio ambiente (Filho; Sena; Almeida; Silva; Silva, 2014).

O óleo não reciclado, descartado indevidamente, provoca danos ambientais e sociais graves, tal como o entupimento de caixas de gordura e tubulações da rede de esgotos, o que produz uma pressão que contribuirá para a infiltração desse óleo no solo, podendo atingir lençóis freáticos ou gerar um refluxo do esgoto à superfície através da própria rede (Gomes; Chaves; Barbosa; Barbosa 2013). A contaminação das águas próximas ao local de descarte de um litro de óleo pode infectar cerca de um milhão de litros de água, volume correspondente ao que um indivíduo consome durante, aproximadamente, quatorze anos de sua vida (Berkenbrock, 2009).

À vista disso, o Projeto Sabão Ecológico tem-se mostrado uma alternativa sustentável para o descarte de óleo usado, reduzindo o impacto ambiental que este pode trazer para o município de Viçosa e regiões vizinhas, além de ser uma ferramenta educacional capaz de melhorar a maneira como os envolvidos se relacionam com o ambiente à sua volta, garantindo uma maior segurança ambiental aos locais impactados e suas proximidades.

\section{Objetivos}

\section{Objetivo Geral}

Promover o desenvolvimento socioambiental da comunidade de Viçosa, a partir de oficinas que buscam esclarecer os danos que o descarte incorreto de óleo usado pode causar ao meio ambiente, e ensinar a reciclar o mesmo através da produção de um sabão artesanal.

\section{Objetivos Específicos}

- Levantar informações sobre o consumo do óleo de cozinha, bem como a forma como este é descartado no município de Viçosa;

- Estruturar e adaptar oficinas de educação ambiental para serem realizadas com públicos de diferentes idades, incluindo desde crianças matriculadas no $6^{\circ}$ ano do Ensino Fundamental II até idosos;

- Conscientizar a comunidade de Viçosa a respeito do descarte inadequado do óleo de cozinha usado, por meio de oficinas;

- Ensinar aos participantes das oficinas uma forma sustentável de destinar o óleo de cozinha já utilizado, sendo essa por meio da produção de um sabão artesanal.

\section{Metodologia}

\section{Levantamento de informações sobre consumo e descarte de óleo de cozinha}

Durante o primeiro semestre de 2017, o Projeto Sabão Ecológico levantou informações sobre o consumo de óleo e a forma como este era descartado na cidade de Viçosa, de forma a obter dados capazes de permitir uma avaliação sobre o comportamento dos viçosenses frente ao meio ambiente. Assim, buscou-se validar a necessidade de continuidade do projeto, bem como avaliar quais as melhores frentes de atuação para sanar os problemas encontrados, aprimorando o trabalho que vem sendo desenvolvido pela ONG Engenheiros Sem Fronteiras.

Tais informações foram obtidas a partir de um questionário on-line, dividido em três seções, cada qual com seu objetivo particular. Na primeira, foram coletadas informações relativas ao perfil dos respondentes; a segunda objetivou recolher dados sobre o consumo de óleo e a terceira teve por finalidade 
avaliar como as pessoas, atualmente, descartam o óleo consumido e o quão dispostas estão a mudar esse hábito.

As perguntas elaboradas (Anexo 1), que continham os propósitos mencionados, foram confeccionadas visando à maior objetividade possível, de forma a evitar problemas de interpretação e facilitar o preenchimento.

\section{Estruturação da oficina de capacitação}

Desde a criação do Projeto Sabão Ecológico no ano de 2016, as oficinas eram realizadas em locais públicos e abertos, tal como em praças públicas de diversos bairros, com o intuito de atingir a população interessada que residisse próximo ao local. Neste modelo, a oficina tinha como único objetivo ensinar a produção de sabão, tendo em vista que não havia recursos didáticos para abordar as implicações econômicas, sociais e ambientais que o projeto poderia promover. Além disso, havia dificuldades em controlar o número de participantes, avaliar a qualidade da oficina e mensurar o impacto do projeto na comunidade envolvida.

Visando otimizar os resultados alcançados pelo projeto, ampliar seus objetivos e melhorar sua estrutura, no início do ano de 2017, a metodologia utilizada para a realização das oficinas foi repensada e modificada. No novo modelo, a oficina passou a ter como foco principal a atuação em escolas de Ensino Fundamental II e Ensino Médio, apesar de ainda atuar em outros espaços, de acordo com demandas apresentadas. Esta faixa etária foi escolhida devido ao potencial de mudança inerente às crianças e adolescentes, tendo em vista que estão em um período em que suas opiniões, impressões e crenças estão sendo formadas. Contribuir para que entendam a necessidade de se preservar o meio ambiente e oferecer uma ferramenta para tal, se mostrou um meio eficiente de maximizar os impactos do Projeto Sabão Ecológico.

Além de modificar o público alvo do projeto, também foi alterada a estrutura das oficinas, que foram divididas em duas modalidades: teórica e prática. Ao longo da modalidade teórica é explorada a poluição, de uma maneira geral, e o impacto da mesma sobre o meio ambiente e a sociedade. Em seguida, o assunto é detalhado, buscando-se focar, exclusivamente, na poluição das águas causada pelo descarte incorreto de óleo de cozinha. Após isso, é abordada a interação química entre água e óleo e como é possível produzir sabão a partir do óleo usado. Posteriormente, é apresentada a receita de sabão e os cuidados que se deve ter durante a produção e, finalmente, é feita uma análise de custo/benefício dessa receita, indicando a vantagem econômica de se produzir o sabão e aventando a possibilidade de venda. Já a modalidade prática, demonstra a produção de sabão de uma maneira dinâmica, ensinando os participantes a fazê-lo com total segurança e garantia de resultados.

Por fim, ainda foi acrescentada às oficinas, a aplicação de um questionário cujo objetivo é mensurar a qualidade das mesmas, de acordo com as percepções dos participantes, assunto que será detalhado posteriormente.

\section{Desenvolvimento do material didático}

Durante o mês de julho de 2016, o Projeto Sabão Ecológico ofereceu um minicurso intitulado "Produção de Sabão Ecológico", na 87a Semana do Fazendeiro da Universidade Federal de Viçosa, para o qual foi desenvolvida uma apostila. A confecção dessa teve como objetivo apresentar, de forma concisa, os prejuízos que o descarte incorreto de óleo usado pode trazer para o meio ambiente e para a sociedade, os mecanismos químicos básicos que envolvem a produção e ação dos sabões, fornecer a receita a ser utilizada e expor a análise de custo que envolve a produção do sabão ecológico.

Devido aos resultados altamente positivos alcançados ao longo desse minicurso, identificou-se uma necessidade de desenvolver um material impresso semelhante para ser distribuído entre os participantes das oficinas, de forma a auxiliar o acompanhamento das mesmas. Desta forma, com base na apostila desenvolvida para a $87^{\mathrm{a}}$ Semana do Fazendeiro da UFV, os membros do Projeto Sabão Ecológico produziram uma cartilha que foi entregue aos participantes das oficinas. Para complementar, foram elaborados uma apresentação, em slides, que completa e detalha os assuntos abordados na cartilha, e um banner, baseado na apresentação em slides, para ser usado em locais onde não há a possibilidade de uso de um projetor. 


\section{Formulação do sabão em barra}

A receita de sabão em barra utilizado pelo Projeto Sabão Ecológico em suas oficinas, foi desenvolvida pelos próprios membros do projeto e é constantemente aperfeiçoada, para tornar a qualidade do produto final ainda melhor. A receita atual necessita dos seguintes reagentes:

- 2 L de água;

- 6 L de óleo usado;

- $1 \mathrm{Kg}$ de soda cáustica em escamas;

- Aproximadamente $50 \mathrm{~mL}$ de essência para material de limpeza.

Além dos reagentes citados, são necessários os seguintes materiais:

- 1 funil;

- 1 unidade de palha de aço;

- 1 galão para armazenar o óleo filtrado;

- 1 balde plástico de, aproximadamente, $30 \mathrm{~L}$;

- 1 colher de madeira grande;

- 1 vasilha plástica de, aproximadamente, $10 \mathrm{~L}$;

- 1 faca;

- 1 par de luvas;

- 1 unidade de máscara.

Primeiramente é necessário realizar o processo de filtração do óleo usado, de forma a retirar todas as impurezas e garantir a qualidade do sabão que será posteriormente produzido. Para isso, deve-se recobrir um funil com a palha de aço, constatado como o melhor material para a filtração, uma vez que possui uma malha fina, com pequenos poros, capaz de proporcionar uma boa retenção da borra. O óleo é, então, cuidadosamente vertido no funil e depositado em um galão higienizado.

Após o processo de filtragem é possível iniciar, de fato, a produção do sabão. No balde plástico é depositada toda a água. A seguir é acrescentada, vagarosamente, a soda cáustica em escamas, tendo o cuidado de agitar a mistura durante a dissolução desses reagentes. Durante esta etapa haverá a liberação de vapor de água com partículas de soda cáustica e calor, assim, para manter a segurança pessoal é necessário o uso de luvas, máscara, calça, blusa de manga comprida e calçado fechado.

Após toda dissolução da soda na água, mistura que apresenta uma coloração esbranquiçada, é adicionado o óleo usado já filtrado. Este deverá ser acrescentado em pequenas porções, sendo necessário manter a agitação durante todo o processo para obter uma homogeneização adequada do produto final.

Por último é acrescentada a essência, para neutralizar o cheiro do óleo e inserir um aroma agradável, conforme a preferência da pessoa que está produzindo o sabão.

Finalizado esse passo, é necessário continuar agitando a mistura por cerca de quinze minutos. A seguir, o sabão, que ainda não está pronto, é vertido na vasilha plástica para passar pelo processo de branqueamento e secagem durante, aproximadamente, sete dias.

Quando o produto estiver branco e completamente firme, deve-se parti-lo com o auxílio de uma faca. Antes disso, não é recomendada a utilização de materiais metálicos, devido à propriedade da soda cáustica de corroer esse tipo de material.

\section{Avaliação das oficinas}

Ao final de cada oficina é aplicado aos participantes um questionário de avaliação da mesma, com o intuito de coletar informações referentes à qualidade dos materiais utilizados no curso, da apresentação e do sabão artesanal produzido. As percepções dos participantes são coletadas por meio de perguntas objetivas que oferecem cinco opções de resposta, possibilitando ao participante classificar as oficinas em uma escala que vai desde "excelente" até "péssimo" (Anexo 02).

O feedback dado pelos participantes das oficinas é fundamental para o processo de aprimoramento do Projeto Sabão Ecológico, pois as informações geradas permitem aos voluntários do projeto identificar as falhas do mesmo, propiciando a tomada de ações corretivas que visam ao maior êxito do trabalho executado. 


\section{Resultados e Discussão}

\section{Consumo e descarte de óleo de cozinha em Viçosa e região}

O Projeto Sabão Ecológico aplicou um questionário on-line entre os dias 1 de maio de 2017 e 30 de junho de 2017 com o intuito de obter informações para mensurar o consumo de óleo e avaliar a maneira como este é descartado na cidade de Viçosa, conforme já foi explicitado.

Esse questionário foi respondido por indivíduos de 14 a 50 anos, dos quais 77,9\% são estudantes de ensino médio ou superior (graduação e pós-graduação). Este dado reflete a realidade de Viçosa, cidade que possui uma população estimada de 78.381 de pessoas (IBGE, 2017), mas que se calcula que, desta parcela, cerca de 20 mil habitantes seja composto por uma população flutuante significativa formada por estudantes, tendo em vista que abriga duas universidades, a Universidade Federal de Viçosa e a Univiçosa (Marin, 2016).

Segundo a pesquisa, 62,3\% dos indivíduos consomem menos de 1 litro de óleo de cozinha por mês, 23,6\% consomem entre 1 e 2 litros de óleo e 14,1\% consomem mais de 2 litros de óleo mensais, indicando um baixo consumo deste item. Este dado pode ter relação com a grande quantidade de estudantes que participaram da pesquisa, já que esta parcela populacional consome poucas refeições em casa, sendo estas, majoritariamente, compostas por café da manhã e lanches, que não utilizam o óleo como ingrediente.

Sobre o preparo de alimentos, foi constatado que 8,5\% dos moradores não fazem frituras em casa, como consequência, eles não geram óleo para descarte. Além destes, 55,7\% dos entrevistados raramente fazem fritura e $25,5 \%$ fazem fritura cerca de uma vez por semana, produzindo um pequeno volume de óleo para descarte. Por último, tem-se que 10,3\% fazem fritura cerca de três vezes ou mais por semana. O óleo proveniente desse percentual da população pode impactar negativamente o ambiente que os cerca, caso os mesmos não possuam consciência ambiental.

Em relação ao descarte do óleo usado, os resultados indicaram que 23,6\% dos indivíduos o descartam diretamente na pia, poluindo as águas de abastecimento da região e $28,3 \%$ o descartam no lixo, acondicionado em uma garrafa pet. Em longo prazo, este descarte pode poluir o solo, alcançando o lençol freático. Por fim, $0,9 \%$ o descartam, diretamente, no solo, poluindo o solo e o lençol freático. Esses dados representam $52,8 \%$ dos indivíduos entrevistados que praticam um descarte inadequado do óleo e prejudicam tanto as águas como o solo da região onde vivem, provavelmente devido à falta de conhecimento a cerca dos malefícios que essa prática pode proporcionar (Costa; Lopes; Lopes, 2015).

Apesar dos dados coletados, $100 \%$ dos entrevistados sugeriram um descarte ecologicamente correto, quando foram questionados sobre o melhor destino para o óleo usado. A sugestão mais frequente foi a produção de sabão, seguida pela produção de combustível, que são produtos que podem ser fabricados de maneira sustentável através do processo de reciclagem do óleo de cozinha (Junior; Neto; Lima, 2009). Isto permite inferir que mesmo a parcela que atualmente pratica um descarte inadequado, está disposta a aprender novas formas de lidar com o meio ambiente, promovendo, de fato, sua preservação.

Como o foco maior deste projeto é a produção de sabão a partir de óleo usado, buscou-se averiguar qual o conhecimento que os entrevistados possuíam desse método de reciclagem do óleo.

Foi verificado que $84,9 \%$ dos entrevistados conhecem pelo menos uma pessoa que saiba fazer sabão à base de óleo. Deste total, 29,2\% conhecem mais de cinco pessoas que saibam fazer sabão. Ainda foi observado que $74,5 \%$ dos indivíduos já usaram sabão feito à base de óleo usado, sendo que destes, $70,9 \%$ gostaram do produto. Dos $25,5 \%$ que nunca usaram este tipo de sabão artesanal, $88,9 \%$ usariam o sabão para, em princípio, experimentar o produto. Estes dados demonstram a aceitação deste produto artesanal entre a população pesquisada, reforçando a utilização deste método de reciclagem como o ideal, que, além desses fatores, ainda mostra uma alternativa a ser empregada para a economia de água, devido a um menor índice de espuma que produz (Rabelo; Ferreira, 2008).

Objetivando verificar a importância das oficinas do projeto em questão, foi constatado que 52,8\% dos indivíduos entrevistados afirmaram que gostariam de aprender a fazer o sabão. Dos indivíduos que não mostraram interesse neste aprendizado, $24,5 \%$ já sabem fazer o produto. Portanto, os dados indicam que o projeto ainda tem um público interessado nas oficinas, bem como no contato com a produção de sabão como medida de preservação ambiental. 
Por fim, foi averiguado que 74,5\% dos indivíduos pesquisados gostariam de comprar sabão à base de óleo e $17 \%$ não comprariam o produto. O público restante prefere consumir o sabão que já produz. Estes dados comprovam a existência de um mercado consumidor neste ramo e também demonstram a possibilidade de geração de renda com o excedente da produção, conforme é incentivado nas oficinas do Projeto Sabão Ecológico.

\section{Caracterização das oficinas do Projeto Sabão Ecológico}

A oficina do projeto em questão é dividida em duas modalidades, teórica e prática, de forma a maximizar a compreensão e absorção do conteúdo abordado. Assim, antes de abordar a produção de sabão a base de óleo em si, trabalha-se a questão da poluição ambiental, em especial a poluição decorrente do descarte inadequado do óleo proveniente de frituras e, posteriormente, o mecanismo químico por trás da ação do sabão. Dessa forma, a modalidade teórica tem como foco principal a educação ambiental dos indivíduos, ressaltando a real importância de se reciclar o óleo de cozinha utilizado e contribui para promover uma mudança comportamental nos participantes.

A modalidade prática, por sua vez, foca no processo de produção do sabão ecológico, ressaltando as medidas de segurança pessoal, com o objetivo de evitar eventuais acidentes, além de evidenciar as peculiaridades da receita, de forma a conseguir um sabão de qualidade.

Durante a modalidade prática, os participantes só poderão observar o sabão antes de sua secagem. Neste estágio de sua produção, o mesmo possui um aspecto muito distinto do final, com coloração amarronzada (Figura1) que, muitas vezes, leva os participantes ao questionamento sobre a qualidade do produto final.

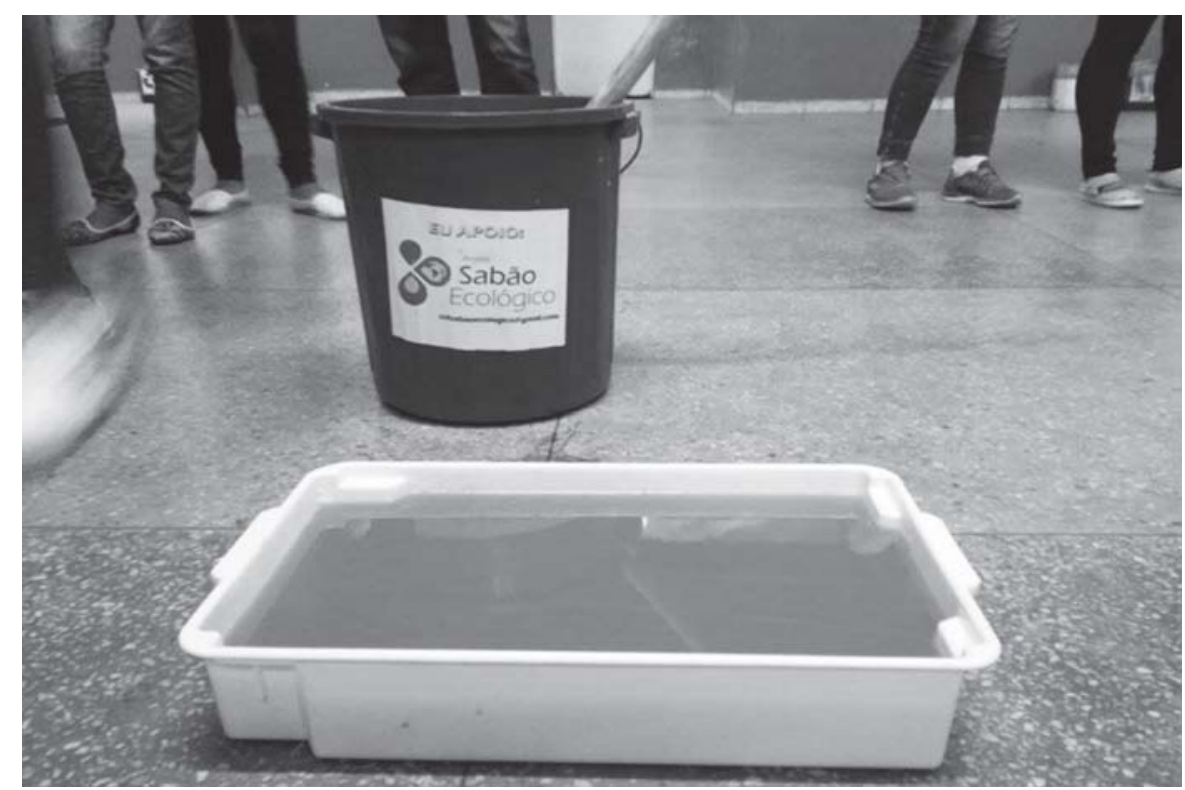

Figura 1: Foto do sabão produzido pelo Projeto Sabão Ecológico antes da secagem.

Fonte: Arquivo da ONG Engenheiros Sem Fronteiras - Núcleo Viçosa

Para evitar dúvidas sobre a qualidade do sabão fabricado, são disponibilizadas amostras de sabão pronto para o uso (Figura 2), para cada um dos impactados, de maneira que eles possam avaliar o resultado final do processo de fabricação. Esta etapa da oficina também é útil para ensinar aos participantes o "ponto" em que o sabão estará pronto para o uso, evitando que se faça uso do mesmo antes do término do processo de secagem, quando ainda há reação da soda, sendo sua utilização nociva à pele.

A partir desse modelo de oficina, foram realizadas outras três, ao longo do primeiro semestre do ano de 2017. A primeira oficina foi feita na sede do ESF - Núcleo Viçosa (Figura 3) com o objetivo de educar os membros sobre o tema e capacitá-los para produzir sabão à base de óleo usado, tornandoos multiplicadores dos ideais do projeto e permitindo que todos possam ser alcançados pela mudança comportamental visada pelo mesmo. 


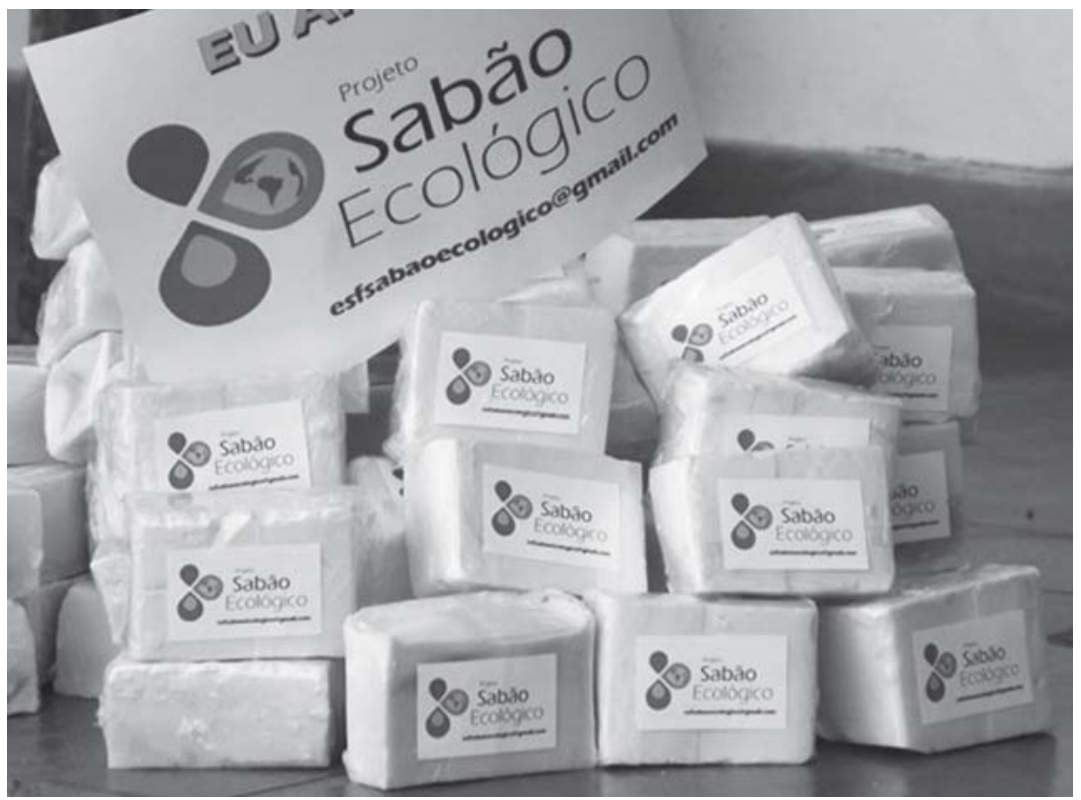

Figura 2 - Foto do sabão produzido pelo Projeto Sabão Ecológico.

Fonte: Arquivo da ONG Engenheiros Sem Fronteiras - Núcleo Viçosa

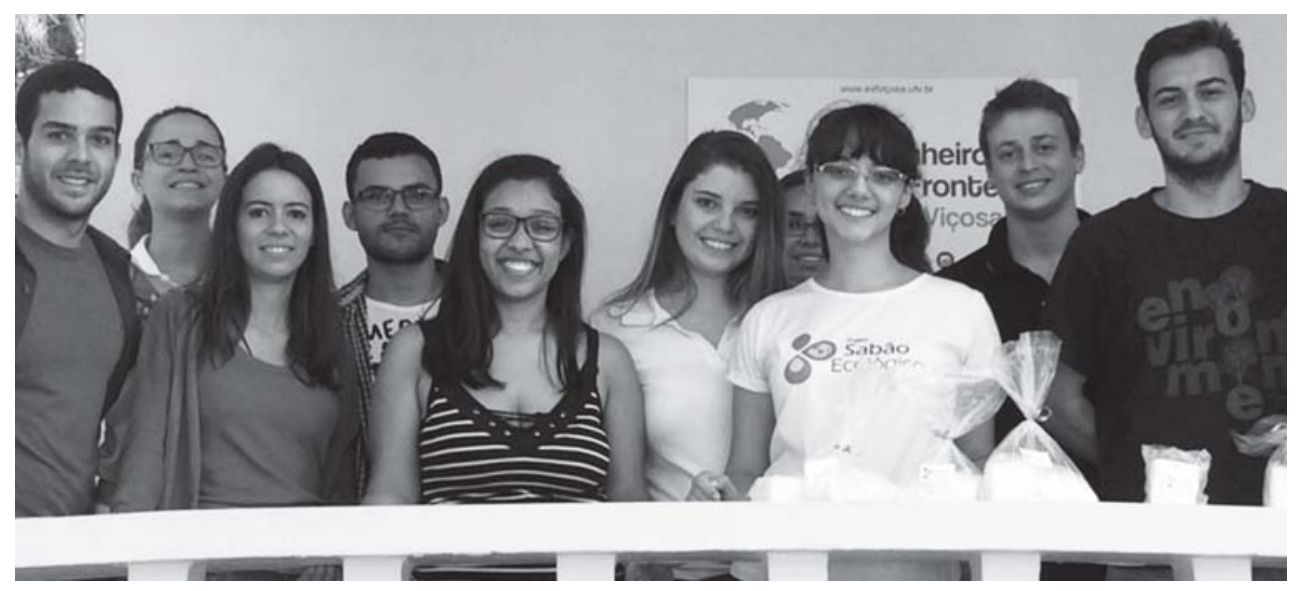

Figura 3 - Foto dos membros participantes da oficina realizada na ONG Engenheiros Sem Fronteiras Núcleo Viçosa.

Fonte: Arquivo da ONG Engenheiros Sem Fronteiras - Núcleo Viçosa

A segunda oficina foi realizada no Colégio Pró-Efeito da cidade de Viçosa, mais especificamente para as turmas do Ensino Fundamental II. Nesta, a modalidade teórica foi adaptada ao modelo de palestra, adequando sua linguagem ao público específico, de forma que todos os participantes obtivessem uma compreensão adequada do tema. A oficina focou, especialmente, o potencial empreendedor do projeto, a pedido da coordenação do colégio, com o objetivo de instigar os alunos. A modalidade prática, por sua vez, foi demonstrativa, onde todos os participantes puderam acompanhar o processo de fabricação e observar os aspectos de cada estágio do produto. Por fim, cada aluno recebeu uma amostra do sabão pronto, podendo visualizar a diferença proporcionada pela etapa de secagem no produto pronto para uso.

A última oficina foi realizada na Casa da Terceira Idade da cidade de Viçosa, localizada na Vila Giannetti - UFV, sendo realizada em um modelo bastante informal, de maneira a facilitar a troca de informações entre os participantes que, em sua maioria, já conheciam alguma receita para confeccionar sabão à base de óleo usado, e os membros voluntários do projeto, que tinham como objetivo principal mostrar a importância do ponto de vista ambiental e da reciclagem do óleo de cozinha usado.

Assim sendo, cada uma das oficinas realizadas, neste ano de 2017, seguiu o modelo inicialmente proposto, mas também foram moldadas de maneira a atender as necessidades de cada encontro, de forma a conseguir os melhores resultados possíveis para a comunidade envolvida e para o meio ambiente. 


\section{Recursos didáticos}

O material didático utilizado pelo Projeto Sabão Ecológico foi desenvolvido de forma a maximizar o aprendizado dos participantes, fornecendo-lhes todos os recursos visuais, através de textos e figuras ilustrativas, necessários para que tenham um acompanhamento adequado das explicações transmitidas nas modalidades teórica e prática das oficinas. Durante a modalidade teórica, sempre que possível, é utilizada uma apresentação padrão, em slides, em conjunto com a cartilha, que é distribuída para todos os participantes.

A apresentação em slides inicia-se com a apresentação do Projeto Sabão Ecológico, abordando um pouco o papel da ONG Engenheiros Sem Fronteiras - Núcleo Viçosa. A seguir, são discutidos, superficialmente, os tipos de poluição e como nossas ações podem maximizar os prejuízos ao meio ambiente e, consequentemente, à sociedade. A discussão é conduzida até o tema de maior interesse do projeto, ou seja, a poluição causada pelo descarte inadequado de óleo de cozinha proveniente de frituras.

A apresentação, então, busca explicar o porquê dessa poluição ser tão danosa e como a interação química entre o óleo e a água maximiza o poder poluidor desse resíduo maléfico. A partir deste ponto são introduzidas as formas de reciclagem do óleo, aprofundando na produção de sabão, com destaque para os aspectos químicos envolvidos no processo e finalizando com a produção, propriamente dita.

A apresentação é finalizada com a análise de custo da receita de sabão, de forma a reforçar a ideia de economia de renda proporcionada por esta prática. Além disso, apresenta-se um pequeno estudo relativo aos possíveis lucros obtidos a partir da venda deste sabão, de forma a incentivar a iniciativa empreendedora dos participantes das oficinas.

A cartilha (Figura 4), mais resumida que a apresentação em slides e com foco maior na produção de sabão propriamente dita, inicia-se introduzindo o aspecto prejudicial do descarte inadequado do óleo, esclarecendo quais os principais males causados por essa prática inadequada. Em seguida, a cartilha apresenta o Projeto Sabão Ecológico, expondo, brevemente, seus objetivos. Por fim, ela trata da produção de sabão, dividindo esta parte em quatro tópicos, de forma a esclarecer quais os cuidados necessários que devem ser tomados antes da produção do sabão a base de óleo e após a produção, garantindo, assim, a segurança de quem fará a reciclagem do óleo usado. A cartilha utilizada auxilia os voluntários do projeto, servindo de base para as oficinas e permitindo adaptar as explicações de acordo com o nível de escolaridade dos participantes. Este recurso é fundamental para garantir uma comunicação efetiva e um aprendizado adequado, independentemente dos conhecimentos prévios dos participantes.

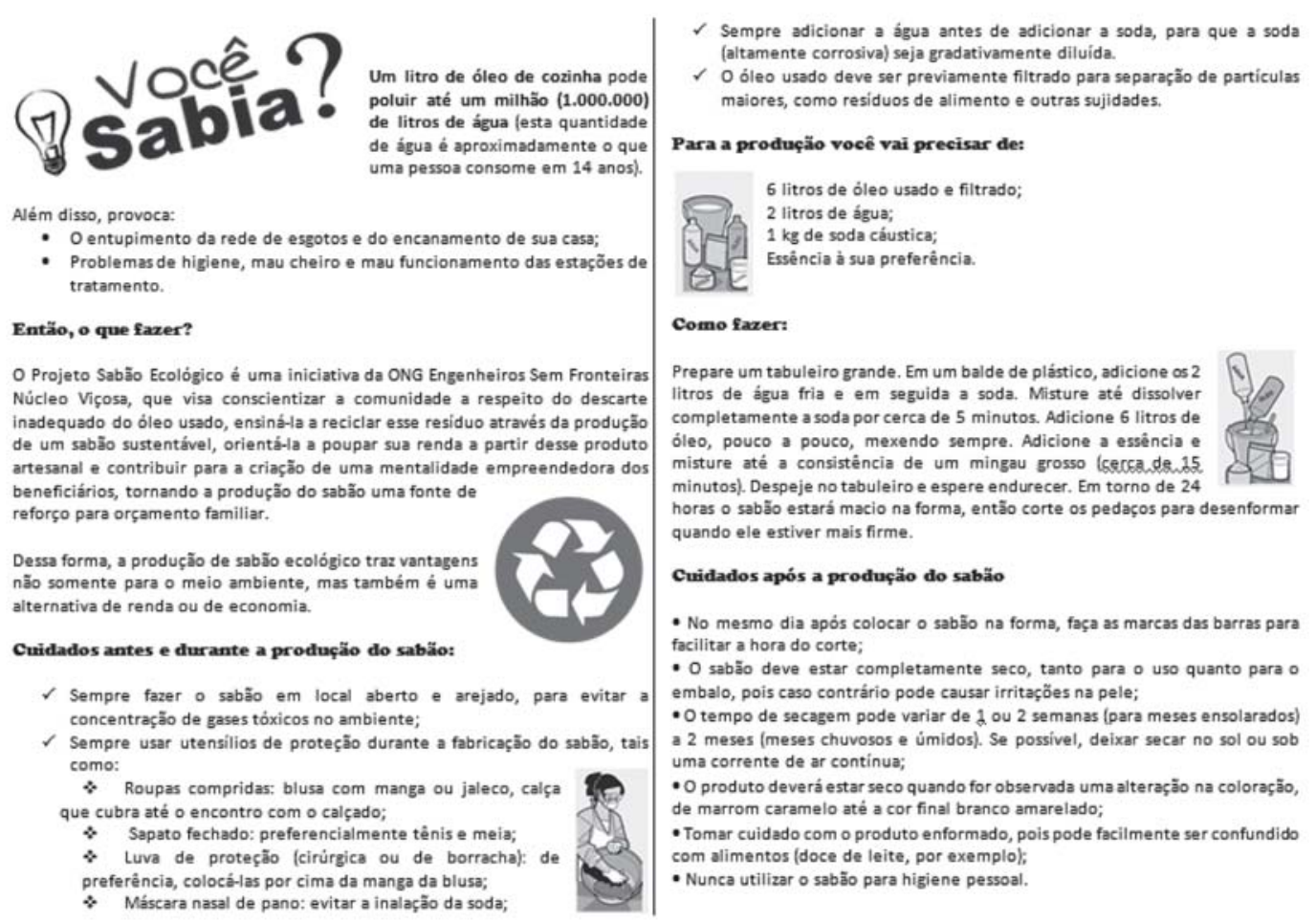

Figura 4: Parte da cartilha utilizada pelo Projeto Sabão Ecológico

Fonte: Elaborado pelos autores. 
O projeto ainda utiliza um banner, cujo objetivo é melhorar a compreensão das etapas envolvidas no processo de fabricação, por meio de uma apresentação mais pedagógica, facilitando o acompanhamento dos participantes durante a demonstração da produção de sabão. De maneira análoga à cartilha, o banner tem como maior foco a produção do sabão, embora também inclua o aspecto poluidor do óleo descartado inadequadamente. Este material é utilizado, invariavelmente, na modalidade prática, em conjunto com a cartilha.

\section{Avaliação das oficinas}

O feedback se mostrou necessário por ser a única ferramenta disponível para mensurar o impacto das atividades e ferramentas avaliadas, dando ao avaliador a oportunidade de comunicar pontos a serem aprimorados e permitindo que iniciativas que busquem o aperfeiçoamento, sejam desenvolvidas (Amaral; Abreu; Silva, 2010). As oficinas foram completamente avaliadas pelos participantes em formulário próprio (Anexo 2), incluindo os materiais utilizados e as apresentações teóricas e práticas. A Tabela 1 demonstra os principais resultados obtidos na avaliação.

Tabela 1 - Resultados obtidos na avaliação das oficinas

\begin{tabular}{lcccccc}
\hline \multicolumn{1}{c}{ Pergunta } & Excelente & Bom & Regular & Ruim & Péssimo & Não se aplica* $^{*}$ \\
\hline Qualidade da cartilha & $37,25 \%$ & $54,90 \%$ & $7,84 \%$ & $0 \%$ & $0 \%$ & - \\
Qualidade dos slides & $21,67 \%$ & $47,06 \%$ & $13,73 \%$ & $1,96 \%$ & $0 \%$ & $15,69 \%$ \\
Qualidade do banner & $41,18 \%$ & $47,06 \%$ & $13,73 \%$ & $1,96 \%$ & $0 \%$ & $15,69 \%$ \\
Qualidade dos materiais & $56,86 \%$ & $33,33 \%$ & $3,92 \%$ & $5,88 \%$ & $0 \%$ & - \\
Qualidade da apresentação teórica & $52,94 \%$ & $35,29 \%$ & $11,76 \%$ & $0 \%$ & $0 \%$ & - \\
Qualidade da apresentação prática & $45,10 \%$ & $43,14 \%$ & $11,76 \%$ & $0 \%$ & $0 \%$ & - \\
Qualidade do sabão & $54,90 \%$ & $39,21 \%$ & $1,96 \%$ & $3,92 \%$ & $0 \%$ & - \\
\hline
\end{tabular}

* Essa opção foi assinalada quando não houve a necessidade ou possibilidade de utilização de um dos recursos didáticos oferecidos pelo Projeto Sabão Ecológico.

Fonte: Elaborado pelos autores

Segundo os dados obtidos é possível observar uma aceitação satisfatória por parte dos participantes das oficinas, da cartilha, slides e banner utilizados. A cartilha recebeu uma avaliação que variou de "regular" a "excelente", sendo majoritariamente classificada como "boa" (54,90\%), tendo apenas uma pequena porcentagem de participantes classificando-a como "excelente" (7,84\%). Isso indica uma necessidade de reformulação da mesma, adaptando-a ao público alvo e inserindo mais elementos visuais, constando na forma de texto apenas informações essenciais sobre o projeto e a produção de sabão em si, pois todas as demais informações são incluídas nos slides.

Com relação aos slides, sua aceitação foi menor do que a cartilha, onde sua avaliação variou de "ruim" a "excelente", sendo classificados como bom por $47,06 \%$ dos participantes. Este dado levanta a possibilidade de que o material não cumpriu adequadamente a função de auxiliar na compreensão das explicações teóricas, demonstrando uma clara necessidade de readaptação ao público, podendo até ser conveniente confeccionar uma apresentação para cada oficina teórica, adequando ao público alvo em questão.

Por fim, tem-se o banner, utilizado nas apresentações práticas, que obteve a melhor avaliação, sendo classificado como "excelente" por $41,18 \%$ dos participantes, o que, provavelmente, é consequência de sua apresentação mais visual entre todos os materiais. Porém, como no caso dos slides, sua avaliação também variou de "ruim" a "excelente".

Os utensílios utilizados na parte prática, tais como baldes, colheres de pau, soda, dentre outros, obtiveram uma alta aceitação por parte dos participantes, tendo em vista que, mais da metade dos envolvidos, avaliaram-os como "excelente". Considerando que são materiais de fácil manuseio e disponíveis nos mercados da cidade, acredita-se que isso facilitará a replicação da produção do sabão à base de óleo com qualidade pelos participantes.

Já em relação às apresentações teórica e prática, percebe-se que a primeira obteve melhor avaliação, quando comparada à segunda, tendo em vista que mais da metade dos participantes classificaram-a como "excelente" (52,94\%). A modalidade prática também foi bem classificada, sendo avaliada como "excelente" por $45,10 \%$ dos participantes. Ambas apresentaram uma escala de avaliação entre "regular" e "excelente", demonstrando uma necessidade de adequação dos materiais didáticos ao público presente nas oficinas, tão diverso e singular. 
Por fim, tem-se a avaliação do sabão que, embora tenha sido avaliado por $54,90 \%$ dos participantes como "excelente", obteve um resultado aquém do esperado, tendo em vista que é o resultado do projeto. No entanto, é possível atribuir tal dado à aparência que o sabão produzido nas oficinas possui antes de sua completa secagem, uma vez que no estágio em que foi avaliado possui uma coloração amarronzada, que lembra o próprio óleo e remete a algo "não puro", aspecto muito distante do produto final, que apresenta coloração branca, semelhante aos sabões comuns. Como os questionários foram preenchidos pelos participantes antes da distribuição do sabão já pronto, eles, provavelmente, tiveram uma impressão errônea da qualidade do produto, sendo importante que, em futuras oficinas, o sabão seja distribuído anteriormente ao preenchimento dos formulários.

Todos estes dados se mostram essenciais para o aperfeiçoamento do projeto, permitindo que os próprios impactados influenciem na forma de atuação do Projeto Sabão Ecológico e possibilitando a adequação constante das oficinas, o que implica em melhores resultados.

\section{Conclusões}

A utilização da educação com ferramenta para garantir o direito inalienável de todo cidadão de usufruir de um meio ambiente equilibrado em termos ecológicos têm se mostrado de grande importância na obtenção de resultados promissores no que tange à conscientização ambiental da sociedade.

O Projeto Sabão Ecológico, baseado nos pilares da educação e sob a crença de que a preservação ambiental é um dever de todos, atuou na promoção do desenvolvimento socioambiental de Viçosa e suas ações, portanto, se mostraram essenciais em uma sociedade cujo comportamento frente ao meio ambiente tem se mostrado inadequado. Neste contexto, a educação ambiental como ferramenta transformadora, auxiliou a comunidade envolvida a modificar o seu comportamento na busca de uma maior segurança ambiental e propôs, também, uma forma de obter maior segurança financeira, com a economia no orçamento ou mesmo com a geração de receitas proporcionada pelo sabão produzido.

\section{Agradecimentos}

À ONG Engenheiros Sem Fronteiras - Núcleo Viçosa, por acreditar na capacidade do Projeto Sabão Ecológico e garantir sua realização e desenvolvimento. Ao Colégio Pró-Efeito e à Casa da Terceira Idade de Viçosa, que acreditaram no potencial do projeto. E, principalmente, a todos os participantes das oficinas, que hoje multiplicam o aprendizado adquirido, ajudando o ESF - Núcleo Viçosa a alcançar seus objetivos.

\section{Referências}

AMARAL, F. F. do; ABREU, M. C. de; SILVA, M. J. M. C. A. Avaliação de desempenho: um estudo sobre a importância do feedback como efetivo resultado na comunicação. Anuário de Produção Acadêmico Docente, Taubaté, SP, v. 4, n. 9, p.27-43, 2010.

BRASIL. Constituição (1988). Constituição da República Federativa do Brasil. Brasília, DF: Senado Federal. Centro Gráfico, 1988. 292 p.

BRASIL. Ministério do Meio Ambiente. Conceitos de Educação Ambiental. Disponível em: <http:// www.mma.gov.br/educacao-ambiental/politica-de-educacao-ambiental>. Acesso em: 15 jul. 2017.

BRASIL. Política Nacional dos Resíduos Sólidos. Brasília, DF: Câmara dos Deputados. Série Legislação, $2^{\circ}$ edição, 2012, 73 p.

COSTA, D. A. da; LOPES, G. R.; LOPES, J. R. Reutilização do óleo de fritura como uma alternativa de amenizar a poluição do solo. Revista Monografias Ambientais, Santa Maria, RS, v. 14, 2015, p. 243-253.

FILHO, S. T.; SENA, M. F. M. de; Almeida, T. M.; SILVA, V. D.; SILVA, E. R. da. Estudo comparativo da toxicidade do sabão produzido com óleo vegetal residual. Revista Eletrônica em Gestão, Educação e Tecnologia Ambiental, Santa Maria, RS, v. 18, mai. 2014, p. 2-6 .

GOMES, A. P.; CHAVES, T. F.; BARBOSA, J. N.; BARBOSA, E. A. A questão do descarte de óleos e gorduras vegetais hidrogenadas residuais em indústrias alimentícias. XXXIII Encontro Nacional de Engenharia de Produção, Salvador, BA, out. 2013. 
GOMES, P. Revista Prosa Verso e Arte. Disponível em: <http://www.revistaprosaversoearte.com/aeducacao-e-a-arma-mais-poderosa-que-voce-pode-usar-para-mudar-o-mundo-nelson-mandela/ $>$. Acesso em: 14 jun. 2017.

Instituto Brasileiro de Geografia e Estatística - IBGE. Disponível em: <http://cidades.ibge.gov.br/ xtras/perfil.php?codmun=317130>. Acesso em: 12 jul. 2017.

KUNZLER, A. A.; SCHIRMANN, A. Proposta de reciclagem para óleos residuais de cozinha a partir da fabricação de sabão. 2011. 37 f. Trabalho de Conclusão de Curso - Universidade Tecnológica Federal do Paraná, Medianeira, PR, 2011.

MARIN, C.; ROSADO, W.; BERNARDI, M. Vereador se Reúne com IBGE para Discutir População Flutuante do Município. Câmara Municipal de Viçosa, Viçosa, 5 dez. 2016.

\section{Anexos}

Anexo 1 - Perguntas utilizadas no questionário de levantamento de dados sobre consumo e descarte de óleo na cidade de Viçosa

1. Perfil

1.1. Qual a sua idade?

1.2. Qual sua profissão?

1.3. Quantas pessoas moram em sua casa?

1.4. Com que frequência você costuma comer em casa?

2. Consumo de óleo

2.1. Quantos litros de óleo você costuma gastar por mês?

2.2. Com que frequência você costuma fazer frituras em sua casa?

3. Descarte de óleo

3.1. Como você descarta seu óleo usado?

3.2. Qual o melhor fim que, em sua opinião, poderia ser dado para o óleo usado?

3.3. Quantas pessoas você conhece que sabem fazer sabão à base de óleo usado?

3.4. Você já usou sabão à base de óleo usado?

3.5. Você gostou do sabão à base de óleo usado?*

3.6. Você usaria sabão à base de óleo usado?*

3.7. Gostaria de aprender a fazer sabão à base de óleo usado?

3.8. Você compraria sabão à base de óleo usado?

*As perguntas 3.5 e 3.6 foram as únicas dependentes da anterior (3.4), uma vez que, quem já havia usado sabão à base de óleo usado, deveria responder a primeira e quem nunca havia usado, a segunda.

\section{Anexo 2 - Perguntas utilizadas no questionário de avaliação das oficinas}

1. Como você classificaria a qualidade da cartilha?

2. Como você classificaria a qualidade dos slides?

3. Como você classificaria a qualidade do banner?

4. Como você classificaria a qualidade dos materiais utilizados na parte prática?

5. Como você classificaria a qualidade da apresentação da modalidade teórica?

6. Como você classificaria a qualidade da apresentação da modalidade prática?

7. Como você classificaria a qualidade do sabão produzido?

Recebido para publicação em 10/9/2017 e aprovado em 23/11/2017. 